\title{
KESEHATAN RAMBUT ANAK DAN REMAJA
}

\section{Hair Health of Children and Teenage}

\author{
Listiana Masyita Dewi ${ }^{1}$, Richard Guntur Bramantio ${ }^{2}$, Najmarani Devi Firdaus ${ }^{2}$ \\ ${ }^{1}$ Departemen Mikrobiologi, Fakultas Kedokteran, Universitas Muhammadiyah Surakarta \\ ${ }^{2}$ Fakultas Kedokteran, Universitas Muhammadiyah Surakarta \\ Korespondensi: Listiana Masyita Dewi. Alamat email: listiana.masyita@ums.ac.id
}

\begin{abstract}
ABSTRAK
Pedikulosis adalah infeksi parasit Pediculus humanus yang menyerang rambut pada seluruh tubuh terutama rambut kepala. Pedikulosis lebih banyak ditemukan pada wanita dengan rentang usia 9-16 tahun, terutama yang tinggal secara berkelompok. Panti Asuhan Yatim Puteri Aisyiyah Cabang Kotta Barat yang berlokasi di Surakarta memiliki 35 anak asuh dari rentang pendidikan SD hingga sarjana. Keluhan kesehatan yang sering dialami oleh penghuni panti asuhan ini adalah gatal pada kulit kepala dan masalah rambut yang menular antar individu. Keluhan ini kemungkinan besar disebabkan oleh penyakit pedikulosis. Solusi yang telah dilakukan hanya dengan membeli obat warung tanpa dosis dan petunjuk penggunaan yang jelas serta belum ada upaya pencegahan penularan yang signifikan. Pemberian edukasi kepada penghuni panti dirasa sangat diperlukan untuk memperbaiki pengetahuan individu mengenai kesehatan rambut dan mengurangi risiko pedikulosis. Kegiatan pengabdian kepada masyarakat ini dilaksanakan dengan memberikan penyuluhan. Peserta juga diberikan pretes dan post-test untuk menilai sejauh mana peningkatan pengetahuan yang mereka dapatkan. Rata-rata skor pretes adalah 3,24 sedangkan rata-rata skor posttest adalah 8,35. Dengan kata lain, terdapat peningkatan pengetahuan peserta hingga $61,16 \%$.
\end{abstract}

Kata Kunci: Pedikulosis, Rambut, Penyuluhan, Pengetahuan

\section{ABSTRACT}

Pediculosis is a parasitic infection caused by Pediculus humanus which attacks the hair on the entire body especially the head hair. Pediculosis is more common in women aged 9-16 years, especially those who live in groups. Panti Asuhan Yatim Puteri Aisyiyah Cabang Kota Barat which is located in Surakarta, has 35 occupants from elementary level to undergraduate. Health complaints that they often experienced are itching of the scalp and hair problems that are transmitted between individuals. This complaint is most likely caused by pediculosis. The solution that has been done is only by consuming over-the counter-drug without clear dosage and usage instructions and there have been no significant prevention efforts. Providing education to the orphanage occupants is needed to improve individual knowledge about hair health and reduce the risk of pediculosis. This community service activity is carried out by providing counseling. Participants were also given a pretest and post-test to assess the extent of the increase in the knowledge they gained. The average pretest score was 3.24, while the average posttest score was 8.35. In other words, there was an increase in the knowledge of participants up to $61.16 \%$.

Keywords: Pediculosis, Hair, Counseling, Knowledge 


\section{PENDAHULUAN}

Pedikulosis merupakan infeksi oleh parasit Pediculus humanus yang dapat menyerang rambut di seluruh bagian tubuh, terutama pada kepala (Djuanda, et al, 2013). Pedikulosis tergolong penyakit yang tidak mengancam jiwa, sehingga seringkali terabaikan dalam pengendaliannya (Doroodgar, et al, 2014).

Insidensi pedikulosis diketahui semakin meningkat dari tahun ke tahun, dan termasuk dalam kelompok neglected disease terutama di Negara-negara miskin dan berkembang di seluruh dunia (Doroodgar, et al, 2014). Penelitian sebelumnya mengatakan bahwa pedikulosis lebih banyak ditemukan pada wanita dibanding laki-laki, terutama pada rentang usia 9-16 tahun (Gulgun, 2013). Hal ini kerap menimbulkan penurunan kepercayaan diri, penurunan kualitas tidur, gangguan belajar, hingga masalah sosial dengan orang lain (Alatas et al., 2013).

Penghuni asrama, panti, maupun lembaga pemasyarakatan memiliki tingkat kontak fisik yang cukup tinggi dan kebiasaan saling pinjam meminjam alat-alat kebutuhan sehari-hari, seperti sisir, handuk, selimut, dan seprei. Alatalat tersebut bilamana telah dipakai oleh seseorang yang telah terinfeksi pedikulosis, maka parasit Pediculus humanus dapat tertinggal padanya. Alat-alat yang telah terkontaminasi bila kemudian digunakan oleh orang lain, maka dapat menjadi perantara penularan pedikulosis (Maryanti, et al, 2018).

Banyaknya panti asuhan anak yang ada di Indonesia turut menjadi salah satu faktor pendukung penyebaran pedikulosis. Jumlah panti asuhan anak di seluruh Indonesia yang teregistrasi Kementerian Sosial mencapai 5.540 lokasi. Jumlah panti asuhan anak khususnya di kota Surakarta sendiri sebanyak 24 lokasi, terdiri dari 2 panti asuhan anak milik pemerintah dan 22 panti asuhan anak milik swasta. Jumlah anak yang diasuh mencapai 5.487 orang (Dinas Sosial Propinsi Jawa Tengah, 2014)

Panti Asuhan Yatim Puteri Aisyiyah Cabang Kotta Barat mengasuh sebanyak 35 anak, yang terdiri dari 11 anak berumur antara 5-10 th dan sedang menjalani pendidikan di Madrasah Ibtidaiyah, 15 anak lainnya menjalani pendidikan di tingkat Madrasah Tsanawiyah, 9 anak sedang menjalani pendidikan di SMA, dan satu anak sedang menajalani pendidikan sarjana di Universitas Muhammadiyah Surakarta. 
Kunjungan pendahuluan ke Panti Asuhan Yatim Puteri Aisyiyah Cabang Kotta Barat didapatkan bahwa keluhan tersering bagi para penghuni panti asuhan adalah keluhan gatal pada kulit kepala dan masalah rambut yang menular antar individu. Solusi yang selama ini dilakukan untuk mengatasi masalah tersebut hanya dengan membeli obat warung tanpa dosis dan petunjuk penggunaan yang jelas. Tidak banyak pula penghuni panti asuhan yang memahami dengan baik mengenai pendidikan kesehatan rambut dan kulit kepala serta pencegahan baik secara primer, sekunder, maupun tersier untuk menjaga kesehatan rambut dan kulit kepala.

\section{TUJUAN DAN MANFAAT}

Pemberian edukasi kepada penghuni panti dirasa sangat diperlukan untuk meningkatkan pengetahuan masing-masing individu mengenai kesehatan rambut dan mengurangi risiko pedikulosis. Seiring dengan adanya peningkatan pengetahuan kesehatan pada tiap individu, maka diharapkan akan terbentuk perilaku hidup bersih dan sehat.

\section{METODE PELAKSANAAN KEGIATAN}

Pengabdian masyarakat ini dilakukan dalam bentuk penyuluhan terhadap penghuni panti untuk mengenalkan kepada penyakit pedikulosis, mulai dari definisi penyebab, faktor risiko, tanda dan gejala, penularan, pencegahan, serta tata laksana awal penyakit pedikulosis. Namun, penyuluhan lebih dititikberatkan pada tindakan pencegahan penularan pedikulosis.

\section{HASIL PELAKSANAAN KEGIATAN}

Kegiatan pengabdian masyarakat ini dilaksanakan pada hari Sabtu, tanggal 29 September 2018, mulai jam 18.00 hingga jam 19.30, di Panti Asuhan Yatim Puteri Aisyiyah Cabang Kotta Barat. Kegiatan diawali dengan pretes sederhana untuk menilai pengetahuan awal penghuni panti tentang pedikulosis. Kegiatan dilanjutkan dengan penyuluhan tentang pedikulosis melalui presentasi dengan media powerpoint dan leaflet, serta diselingi dengan diskusi serta sharing pengalaman para penghuni panti. Kegiatan berikutnya yaitu penilaian akhir dengan posttest untuk mengukur peningkatan pengetahuan penghuni panti tentang pedikulosis. Kegiatan diakhiri dengan sesi ramah tamah berupa penyerahan sejumlah dorprize, kenangkenangan untuk panti asuhan, serta makan malam bersama. 
Hasil evaluasi penilaian pretes dan posttest terhadap 37 peserta kegiatan pengabdian masyarakat ini ditunjukkan dalam grafik berikut

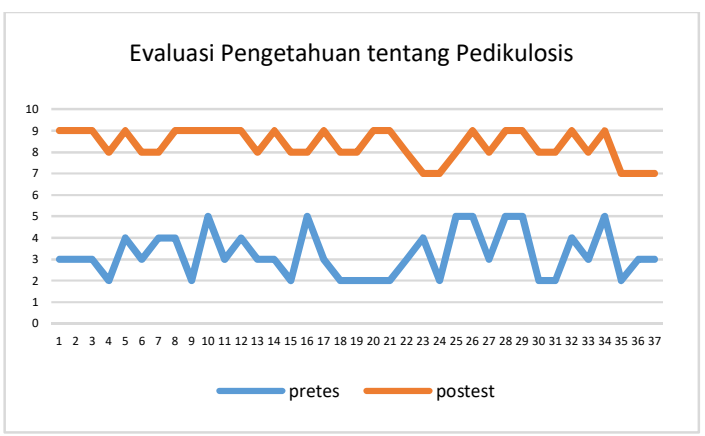

Gambar 1. Perbandingan skor pretes dan posttes

\section{SIMPULAN DAN SARAN}

Berdasarkan grafik di atas, tampak adanya peningkatan skor dari pretes ke posttest, yang menunjukkan adanya peningkatan pengetahuan penghuni panti tentang pedikulosis. Rata-rata skor pretes peserta adalah 3.24, sedangkan ratarata skor posttest peserta adalah 8.35. Atau dengan kata lain, terdapat peningkatan skor hingga $61.16 \%$.

\section{DAFTAR PUSTAKA}

Alatas, S. S. S., Linuwih, S. 2013. Hubungan Tingkat Pengetahuan Mengenai Pedikulosis
Kapitis dengan Karakteristik Demografi Santri Pesantren X, Jakarta Timur. eJKI, Vol (1) 1: 53-57.

Dinas Sosial Propinsi Jawa Tengah, 2014. Banyaknya Panti Asuhan dan Pengelola Menurut Kabupaten/Kota di Jawa Tengah Tahun 2014. http : jateng.bps.go.id/statictable/2015/09/23/110 7/banyaknya-panti-asuhan-dan-pengelolamenurut-kabupaten-kota-di-jawa-tengahtahun-2014.html

Djuanda A, Kosasih A, Wiryadi B.E, Natahusada EC, Daili ES, Effendi EH. Ilmu Penyakit Kulit Dan Kelamin. Cet 3. Jakarta : Fakultas kedokteran Universitas Indonesia; 2013. 119-120.

Doroodgar A, Sadr F, Doroodgar M, Doroodgar Mo, Sayyah M. 2014. Examining the prevalence rate of pediculus capitis infestation according to sex and social factors in primary school children. Asian Pacific Journal of Tropical Disease Vol 4 No. $1: 25-29$.

Gulgun, M., Balci, El., Karaoglu, A., Babacan, O., Turker, T., 2013. Pediculosis capitis: Prevalence and Its Associated Factors in Primary School Children Living in Rural and Urban Areas in Kayseri, Turkey. Cent Eur J Public Health Vol 21(2):104-8.

Maryanti, E. Lesmana, S. D. Novira, M. 2018. Hubungan Faktor Risiko dengan Infestasi Pediculus humanus capitis pada Anak Panti Asuhan di Kota Pekanbaru. Jurnal Kesehatan Melayu. Vol 1 No.2 : 73-80 